|||||||||||||||||||||||||||||||||||||||||||

研究ノート

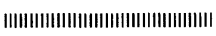

\title{
酸性浴を用いたマグネシウム合金陽極酸化 皮膜の組成と表面状態
}

\author{
千 正男* ·高谷松文* ·松永正久*
}

Film composition and surface appearances of anodized

magnesium alloy in acidic baths

Qian ZENGNAN*, Matsufumi TAKAYA* and Masahisa MATSUNAGA*

(Received December 2, 1988)

\section{1. 緒言}

マグネシウムの陽極酸化皮膜は㙦装下地，耐蝕性，耐 磨耗性を付与する表面処理法として工業的に応用されて いる。この陽極酸化皮膜の形成は酸性あるいはアルカリ 性浴で行われて扣り, 電源には多くの場合交流電源が使 用されている。そして，それぞれの皮膜特性を利用した 実用がなされている。

これらの電解浴から得られた皮膜の組成は, $\mathrm{AC}, \mathrm{DC}$ 電解により $\mathrm{NH}_{4} \mathrm{HF}$ を成分に有機塩を添加した浴 ${ }^{12}$, $\mathrm{NaOH}$ 浴 $^{2}$ および $\mathrm{KOH}$ を主成分とした浴 ${ }^{3) \sim 5)}$ からの皮 膜について検討されているが，その報告は断片的なもの で詳細㰸討されたものは少ないよらである。

本研究は交流電源を用いて酸性浴から形成した酸化皮 膜について，電解条件と皮膜組成および表面状態につい て検討したものである。

\section{2. 実験方法}

陽極酸化処理浴組成は Table 1 亿示すように $\mathrm{NH}_{4} \mathrm{HF}_{2}$ を主成分に $\mathrm{H}_{3} \mathrm{PO}_{4}$ 拈よび $\mathrm{Na}_{2} \mathrm{Cr}_{2} \mathrm{O}_{7}$ (Dow 17 法相当) を添加した 2 種類の酸性浴を用いた。これら浴の建浴の 試薬はいずれも 1 級試薬である。

試料は Table 2 亿示すような化学組成の $\mathrm{Mg}-\mathrm{Mn}$ 合 金（M1）で $\mathrm{Al}$ 含有量が著しく少ない押出材である。電 解実験用試料は $20 \times 15 \times 0.6 \mathrm{~mm}$ の寸法でエメリ一紙 \#800まで機械的な研磨し,ささらに゙フ研磨仕上げ後アセ トンで脱脂処理してただちに電解浴に挿入した。浴温度
Table 1 Bath composition

\begin{tabular}{l|r|r}
\hline \hline & Bath A & Bath B \\
\hline $\mathrm{NH}_{4} \mathrm{HF}$ & $232 \mathrm{~g} / l$ & $282 \mathrm{~g} / l$ \\
$\mathrm{H}_{3} \mathrm{PO}_{4}$ & $88 \mathrm{~g} / l$ & $88 \mathrm{~g} / l$ \\
$\mathrm{Na}_{2} \mathrm{Cr}_{2} \mathrm{O}_{7} .2 \mathrm{H}_{2} \mathrm{O}$ & $0 \mathrm{~g} / l$ & $100 \mathrm{~g} / l$ \\
\hline
\end{tabular}

Table 2 Chemical composition of magnesium alloy

\begin{tabular}{c|c|c|c|c|c|c|c}
\hline \hline \multicolumn{7}{c}{ Chemical composition (\%) } \\
\hline $\mathrm{Fe}$ & $\mathrm{Si}$ & $\mathrm{Zn}$ & $\mathrm{Mn}$ & $\mathrm{Cu}$ & $\mathrm{Ni}$ & $\mathrm{Al}$ & $\mathrm{Mg}$ \\
\hline 0.005 & 0.003 & 0.014 & 0.82 & 0.001 & 0.001 & $17 \mathrm{ppm}$ & $\mathrm{Bal}$. \\
\hline
\end{tabular}

は20，40，60および $80^{\circ} \mathrm{C} て ゙ \pm 2{ }^{\circ} \mathrm{C}$ の精度で調節した。交

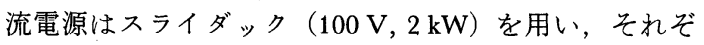
れ所定の電圧に調節した。皮膜の形成法はブレークダウ ンを伴う電圧で処理を行い，そのときの電流密度は5〜 $50 \mathrm{~mA} / \mathrm{cm}^{2}$ の範囲である。皮膜の厚さは断面の SEM 写 真よりもとめた。

皮膜組成同定用皮膜の形成は所定の電解条件で100分 間処理を行い, 水洗, 乾燥後 X 線回折 ( $\mathrm{Cu}$ ターゲット, $30 \mathrm{kV}, 10 \mathrm{~mA}$ ）を行った。また所定の電解条件で形成 した皮膜表面の観察はSEMによって観察した。

\section{3. 実験結果および考察}

\section{1 電解時間と皮膜厚さ}

陽極酸化皮膜の電解時間による厚さの浴種による変化

* 千葉工業大学 (習志野市)。Chiba Institute of Technology (Narashino-shi, Chiba). 
の一例を示したのが Fig. 1である。A 浴では酸化皮膜 の成長は B 浴に比較して著しく小さく, 厚い皮膜の形 成には $\mathrm{Na}_{2} \mathrm{Cr}_{2} \mathrm{O}_{7}$ 塩の添加は有効である。

この皮膜形成の要因については十分に検討を行ってい ないが，筆者等は $\mathrm{KOH}-\mathrm{KF}-\mathrm{Al}(\mathrm{OH})_{3}$ のアルカリ浴か らのマグネシウム合金への皮膜形成がブレークダウン現 象を伴らことによって厚い皮膜形成が可能であることを 報告5) している。A 浴での皮膜形成はふっ化物系塩のち 密で, しか必絶縁性が高く2), そのためブレークダウン 現象は微弱なもので，それに対して B 浴からのものは クロム塩が関係する不動態皮膜の形成が考えられ, A 浴 からの皮膜より絶縁性が低いため, ブレークダウン現象 が活発になり，厚い皮膜の形成となることが考皇られ る。またブレークダウン現象を伴ったときの皮膜表面は A 浴からのものがち密なのに対して B 浴からのそれは 無数の大きな孔が観察されており, 添加金属塩が電極表 面で反応することで皮膜の電導性を改善するため, ブレ 一クダウン現象が皮膜表面に発生しやすくなり，結果と

して厚い粗面となることが考えられる6)。

\section{2 皮膜の $\mathrm{X}$ 線回折}

上述のよ5に $\mathrm{A}$ 浴からの皮膜が薄いため, X 線回折 の諸条件を考慮して B 浴からの皮膜について同定を行 った。Fig. 2 は B 浴で所定の電圧で形成した皮膜の X 線回折の結果を示す。

ブレークダウンを伴ら条件下で形成した皮膜からは $\mathrm{Cr}_{2} \mathrm{O}_{3}$, スピネル構造の $\mathrm{MgCr}_{2} \mathrm{O}_{4}$ および $\mathrm{MgF}_{2}, \mathrm{Mg}_{2}$ $\mathrm{PO}_{4}, \mathrm{MgO}$ のピークが認められるが, 浴温度と印加電 圧によって皮膜の組成が変化している。

印加電圧が低い $(60 \mathrm{~V}, 80 \mathrm{~V})$ 時は浴温度の高い

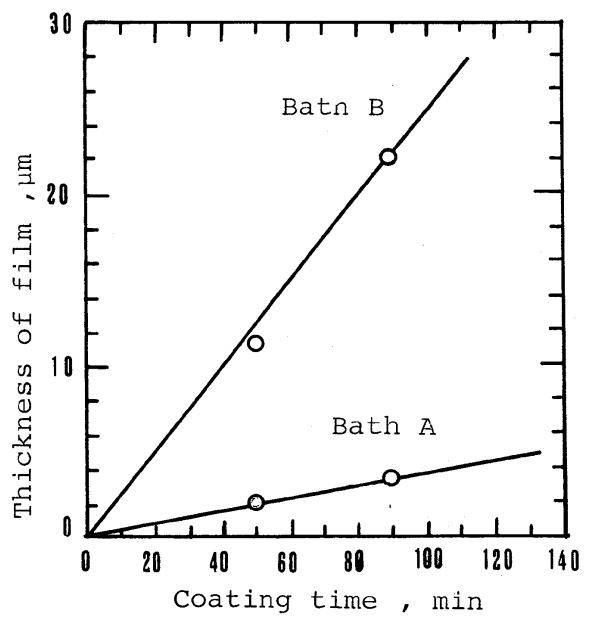

Fig. 1 Relation between thickness of film and coating time in acidic baths $\left(\right.$ at $80^{\circ} \mathrm{C}, 100 \mathrm{~V}, 100$ $\min )$. $\left(80^{\circ} \mathrm{C}\right)$ 場合, $\mathrm{Mg}$ のピークが強く現れ, これは皮膜が 薄いことが考えられる。また皮膜には $\mathrm{Cr}_{2} \mathrm{O}_{3}$ の成分が 認められない。さらに印加電圧を高く（100 V) とした とさは皮膜が厚くなるため $\mathrm{Mg}$ 成分が認められなく， $\mathrm{Cr}_{2} \mathrm{O}_{3}, \mathrm{MgCr}_{2} \mathrm{O}_{4}, \mathrm{MgF}_{2}$ 成分が強く現れている。また皮 膜表面の色彩は暗緑色を呈し, $\mathrm{Cr}_{2} \mathrm{O}_{3}$ 成分が多く含有し ていることが考えられる。

印加電圧が高く, 浴温度が低い場合, スピネル構造の $\mathrm{MgCr}_{2} \mathrm{O}_{4}$ のピークが認められるが, さらに浴温度が $40^{\circ} \mathrm{C}, 100 \mathrm{~V}$ の皮膜からは $\mathrm{MgCr}_{2} \mathrm{O}_{4}$ のピークが認めら

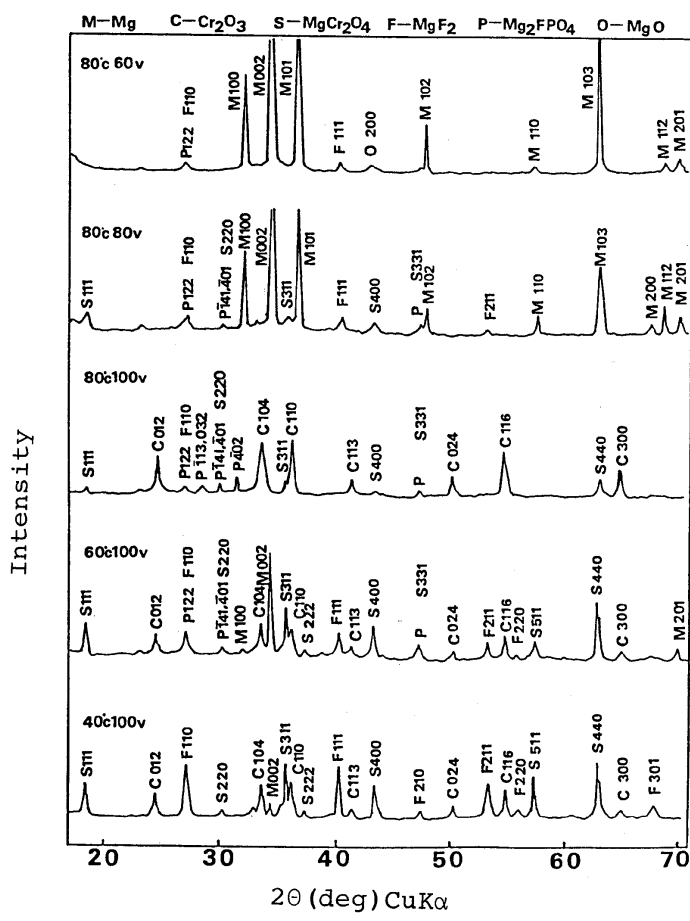

Fig. 2 X-ray diffraction patterns of anodized coating of magnesium in bath $B$ (for $100 \mathrm{~min}$ ).

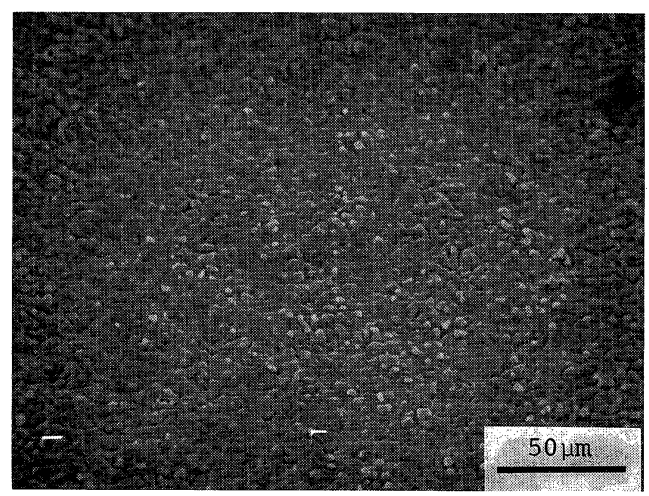

Fig. 3(A) SEM observation of anodized magnesium surface in bath $\mathrm{A}\left(\right.$ at $\left.80^{\circ} \mathrm{C}, 100 \mathrm{~V}, 100 \mathrm{~min}\right)$. 

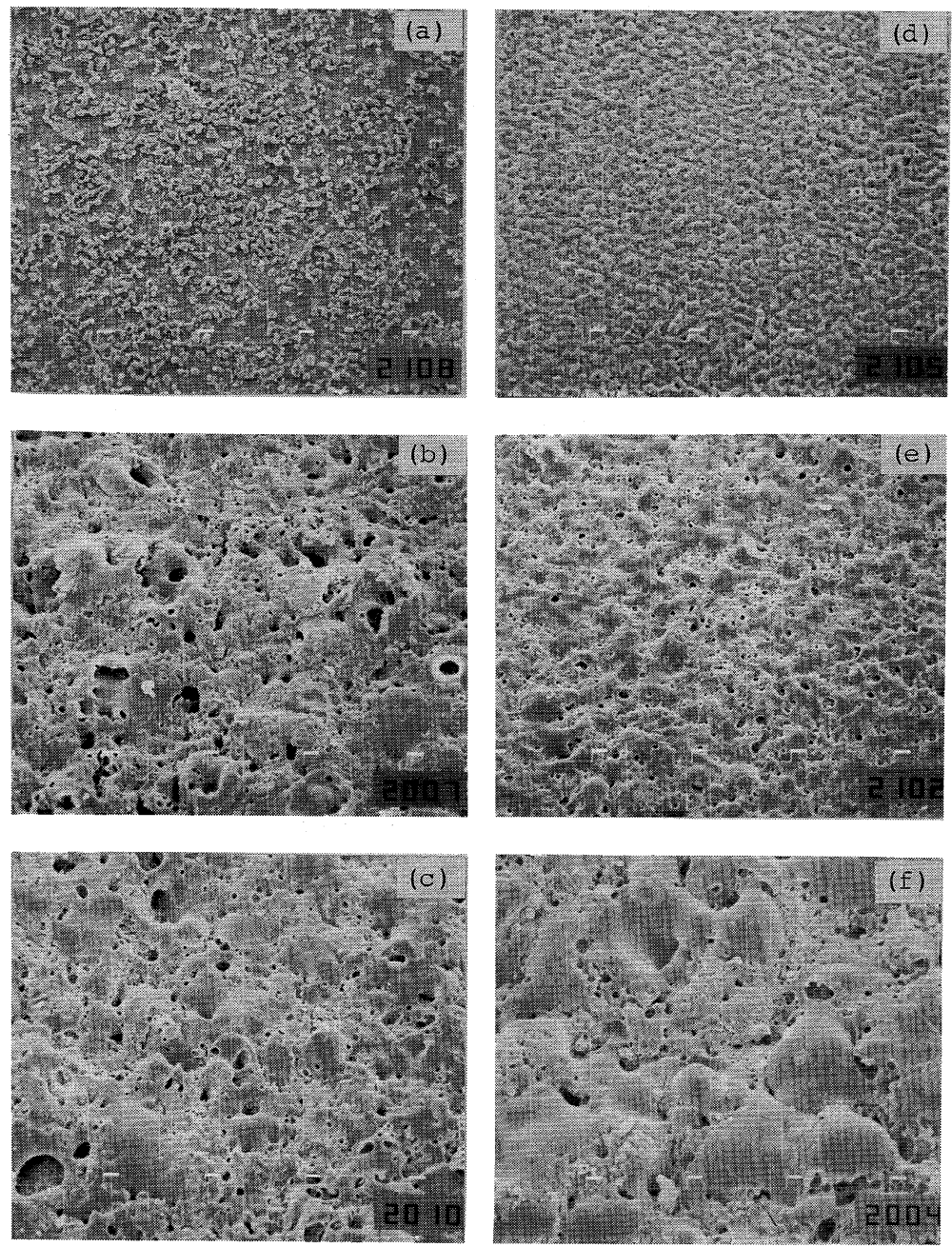

$100 \mu \mathrm{m}$

Fig. 3(B) SEM observation of anodized magnesium surface in bath B. (a): at $20^{\circ} \mathrm{C}, 100 \mathrm{~V}$, (b) : at $40^{\circ} \mathrm{C}, 100$ $\mathrm{V},(\mathrm{c})$ : at $60^{\circ} \mathrm{C}, 100 \mathrm{~V},(\mathrm{~d}):$ at $80^{\circ} \mathrm{C}, 60 \mathrm{~V},(\mathrm{e}):$ at $80^{\circ} \mathrm{C}, 80 \mathrm{~V},(\mathrm{f}):$ at $80^{\circ} \mathrm{C}, 100 \mathrm{~V}$.

れるものの $\mathrm{Mg}_{2} \mathrm{FPO}_{4}$ 成分は検出されない。

\section{3 酸化皮膜の表面状態}

Fig. 3 は陽極酸化皮膜の表面状態を $\mathrm{A}$ 浴からの一例 (A)拉よび B 浴で所定の浴温度, 電圧で100分間処理(B) し たものを示す。

$\mathrm{A}$ 浴からの表面は図に示したように多数の微細粒が観 察されている。B 浴での浴温変化による表面状態は低い $20^{\circ} \mathrm{C}$ の場合, 部分的に塊状成長した皮膜で, $40^{\circ} \mathrm{C}$ と高 くすると表面が粒状で多数の孔が認められ，この傾向は 浴温 $60^{\circ} \mathrm{C} て ゙ も$ 同様である。浴温 $80^{\circ} \mathrm{C}$ としたときの印加 電圧の変化による皮膜表面は $60 \mathrm{~V}$ で比較的平滑な微細 孔が認められるが，電圧を $80,100 \mathrm{~V}$ と高めると孔径は 大きくなり，より粗面化する。

\section{4. 結言}

$\mathrm{NH}_{4} \mathrm{HF}_{2}$ を主成分に $\mathrm{H}_{3} \mathrm{PO}_{4}$ および $\mathrm{Na}_{2} \mathrm{Cr}_{2} \mathrm{O}_{7}$ 塩添加 による酸性浴からマグネシウム合金（M1）を用い， $\mathrm{AC}$ 電源によってブレークダウン状態を保持しながら陽 極酸化皮膜を形成し，皮膜組成の同定抢よび表面観察を 行った結果，以下のことがわかった。

(1) $\mathrm{NH}_{4} \mathrm{HF}_{2}$ に $\mathrm{H}_{3} \mathrm{PO}_{4}$ を添加した浴からの陽極酸化 皮膜の成膜速度は著しく小さいが, $\mathrm{Na}_{2} \mathrm{Cr}_{2} \mathrm{O}_{7}$ 塩を添加 することで改良される。

(2) $\mathrm{Na}_{2} \mathrm{Cr}_{2} \mathrm{O}_{7}$ 添加浴を用いブレークダウンを伴う高 い電圧下での厚い皮膜の組成は $\mathrm{Cr}_{2} \mathrm{O}_{3}, \mathrm{MgCr}_{2} \mathrm{O}_{4}, \mathrm{MgF}_{2}$, $\mathrm{Mg}_{2} \mathrm{FPO}_{4}$ および $\mathrm{MgO}$ の混合相を形成している。 


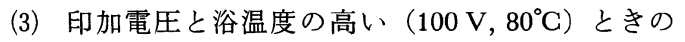
皮膜は $\mathrm{Cr}_{2} \mathrm{O}_{3}$ が多く, そのため表面は暗緑色を呈する。

(4) スピネル構造の $\mathrm{MgCr}_{2} \mathrm{O}_{4}$ は浴温度の高低に拘ら ず印加電圧の高いときに生成される。

（5）酸化皮膜表面は浴温度の低い場合, 微細な孔が観 察されるが浴温度, 印加電圧が高くなるに従って孔が大 きくなり, 表面が粗くなる。

本研究は(財)軽金属奖学会の御援助のもとに行われたも のであり,ここに深甚の謝意を申し上げます。

\section{参 考 文 献}

1) A. E. Yaniv, H. Schick: Plating, 58 (1968), 1295.

2) E. F. Emely: Principle of Magnesium, Pergamon Press, New York, (1966), 114.

3）小林和一, 平沢良和, 高畑 覚: 軽金属学会第66回 春期大会講演概要 (1984), 175.

4) S. Fukushi, M. Takaya: Springer Series in Chemical Physics 44, Springer-Verlag (1984), 175.

5）高谷松文：軽金属，37（1987），581。

6）加藤正義 : 金属表面協会関東支部第 8 回講演会資料, (1986), 4 . 